UDK 631.98

Pregledni rad - Review article

\title{
Fitohormoni, regulatori rastenja biljaka i inhibitori sinteze ili dejstva fitohormona kao agrohemikalije
}

\author{
${ }^{1 *}$ Bogdan Nikolić, ${ }^{2}$ Hadi Waisi, ${ }^{3}$ Vesna Dragićević, ${ }^{4}$ Vladan Jovanović i ${ }^{1}$ Sanja Đurović \\ ${ }^{1}$ Institut za zaštitu bilja i životnu sredinu, Teodora Drajzera 9, 11040 Beograd, Srbija; ${ }^{2}$ Institut za \\ vodoprivredu "Jaroslav Černi", Jaroslava Černog 80, 11226 Beograd, Srbija; ${ }^{3}$ Institut za kukuruz \\ "ZemunPolje", Slobodana Bajića 1, 11185 ZemunPolje, Srbija; ${ }^{4}$ Institut za pesticide i zaštitu životne \\ sredine, Banatska 31b, 11080 Zemun-Beograd, Srbija \\ *e-mail: bogdannik@mail2world.com
}

\section{REZIME}

U radu je dat pregled razvoja istraživanja fitohormona i drugih agrohemikalija, kao herbicida, ali i drugih pesticida, pa i đubriva. Opisan je njihov primarni mehanizam dejstva, ali i nuz-efekti u smislu njihovog uticaja na biljke kao fitohormona, regulatora rastenja ili njihovih inhibitora. Takođe su date sugestije u cilju daljih istraživanja ove teme, jedne od najstarijih u agrotehnici i zaštiti bilja.

Ključne reči: fitohormoni, regulatori ratenja biljaka, inhibicija sinteze i dejstva, pesticidi, dubriva

\section{UVOD}

Pregledom popularne publikacije „Pesticidi u poljoprivredi i šumarstvu u Srbiji“, (Anonymus, 2010) nađeno je preko 40 aktivnih supstanci (i mnogo više preparata), sa fitohormonskim dejstvom, kao i regulatora rastenja biljaka ili inhibitora sinteze ili dejstva fitohormona, bilo kao primarno ili kao sekundarno dejstvo tih pesticida. Ukratko, pesticidi koji modifikuju ili inhibiraju rastenje i razvoj biljaka vrlo su rasprostranjeni u našoj praksi. Ukoliko uzmemo u obzir da nova zakonska rešenja (Anonymus, 2009) za đubriva, uvode kategoriju fitohormona i regulatora rastenja u ovu klasu agrohemikalija, postaje jasna potreba za pregledom ove problematike 


\section{PREGLED I KARAKTERISTIKE RAZLIČITIH KLASA JEDINJENJA SA FITOHORMONSKIM DEJSTVOM ILI NIHOVIH INHIBITORA}

\section{a) analozi auksina}

Iako izgleda da se bez biljnih hormona, bilo u njihovom stimulativnoj ili inhibitornoj funkciji, ne može u fiziologiji biljaka i poljoprivredi (kao primenjenoj biologiji), sama istorija njihovih istraživanja ukazuje da je takav stav stvar novijih vremena. Naime, tek je 1920-tih godina od strane holandskog istraživača Went-a i sovjetskog naučnika Holodnij-a prvi put se došlo do čvrstih saznanja da neke supstance u samim biljkama, u niskim dozama izazivaju izrazite fiziološke i razvojne reakcije (Nešković i sar., 2003). Tada je dokazano da izvesna supstanca, koju sintetiše vršni izdanak biljaka, utiče kako na tzv. apikalnu dominaciju, tako i na izduživanje i deobu ćelija. Pomenuta supstanca je nazvana auksin i uskoro je izvršena i njena hemijska identifikacija, a razvijeni su i odgovarajući biotestovi (tzv. Went-ov Avena test) (Nešković i sar., 2003). Uskoro je postalo jasno da je pomenuti molekul relativno jednostavne hemijske strukture (indol sirćetna kiselina, IAA), pa su se postavila logična pitanja da li je moguća sinteza analognih hemijskih jedinjenja i kakve bi biološke efekte oni izazvali!? Otad su napori hemičara dali rezultate u smislu sinteze čitavog spektra jedinjenja slične hemijske građe prirodnom auksinu (IAA), koje možemo podeliti na: a) indolne derivate, najsličnije IAA (npr. indol-3-buterna kiselina, IBA); b) naftoksi derivate (npr. á-naftalen sirćetna kiselina, NAA); c) fenoksi derivate (2,4-dihlorofenoksi sirćetna kiselina, 2,4-D; 2,4,5-trihlorofenoksi sirćetna kiselina, 2,4,5-T) i d) benzoeve derivate (2,3,6-trijodobenzoeva kiselina, TIBA; 2-metoksi-3,6-dihlorobenzoeva kiselina, DIKAMBA) (Nešković i sar., 2003). Vrlo brzo se pokazalo da neka od ovih jedinjenja imaju toksično dejstvo na širokolisne korove, dok uskolisni usevi (npr. žitarice) dobro podnose dejstvo ovih jedinjenja, ukoliko se primene u određenim razvojnim fazama (Adicott, 1976; Ashton and Crafts, 1973, 1981; Corbett et al., 1984; Janjić 1994). Jednom rečju, tako su izumljeni prvi herbicidi i to tokom Drugog Svetskog rata! Vrlo brzo se pokazalo da pomenuti herbicidi oponašaju dejstvo prirodnih auksina, ali u njihovoj inhibitornoj funkciji, kao kada su biljna tkiva preplavljena velikim dozama auksina, što remeti fiziološke i razvojne procese. Smatra se da je to zbog toga, što za razliku od prirodnih, veštački auksini se mnogo sporije degraduju i njihovo dejstvo u biljkama je mnogo duže odnosno prirodnih auksina (Corbett et al., 1984; Janjić 1994; Nešković i sar., 2003). Mada je u niskim, pa i homeopatskim dozama dejstvo sintetskih auksina vrlo povoljno po biljke (Dragičević et al., 2004, 2007, 2013; Sredojević i sar., 2001), što može biti iskorišteno u praktične svrhe (npr. primena u kulturi biljnih tkiva: Jovanović i sar., 1990; Jovanović et al., 1991), od većeg značaja je inhibitorno dejstvo sintetskih auksina. Kako se ispoljava fitotoksično dejstvo sintetskih auksina, 
tj. fitohormonskih herbicida (Janjić, 1994)? Vrlo rano (Adicott, 1976) je primećeno da sintetski auksini stimulišu sintezu biljnog hormona etilena, karakterističnog za sazrevanje plodova i opadanje lišća, tj. procese tipične za starenje biljaka (Nešković i sar., 2003). Ipak, dugo je smatrano da to nije ključno u fitotoksičnom dejstvu fitohormonskih herbicida, već malformacije pri rastenju i razvoju osetljivih biljaka (širokolisni dikotiledoni korovi, ali i usevi) uslovljene tzv. „over dose“ efektom sintetskih auksina. Svi podaci su ukazivali da se izvitopereno rastenje i razviće osetljivih biljaka može lako objasni tim efektom (Janjić, 1994), ali i dalje je bilo nejasno zbog čega te biljke umiru (Ashton and Crafts, 1973, 1981; Corbett et al., 1984). Tako je bilo dok Grossmann (1996) nije pokazao da se, kao uzgredni produkt biosinteze etilena indukovane od sintetskih auksina, javlja cijanid, čije je toksično dejstvo na razne enzime i procese (npr. disanje) biljaka davno poznato. Neku godinu potom ova hipoteza o fitotoksičkom dejstvu sintetskih auksina proširena je od strane istog autora (Grossmann, 2003) (Slika 1). Pored navedene teme, od praktičnog interesa za dejstvo fitohormonskih herbicida je i proces usvajanja, transporta i metabolizma sintetskih auksina u biljkama.

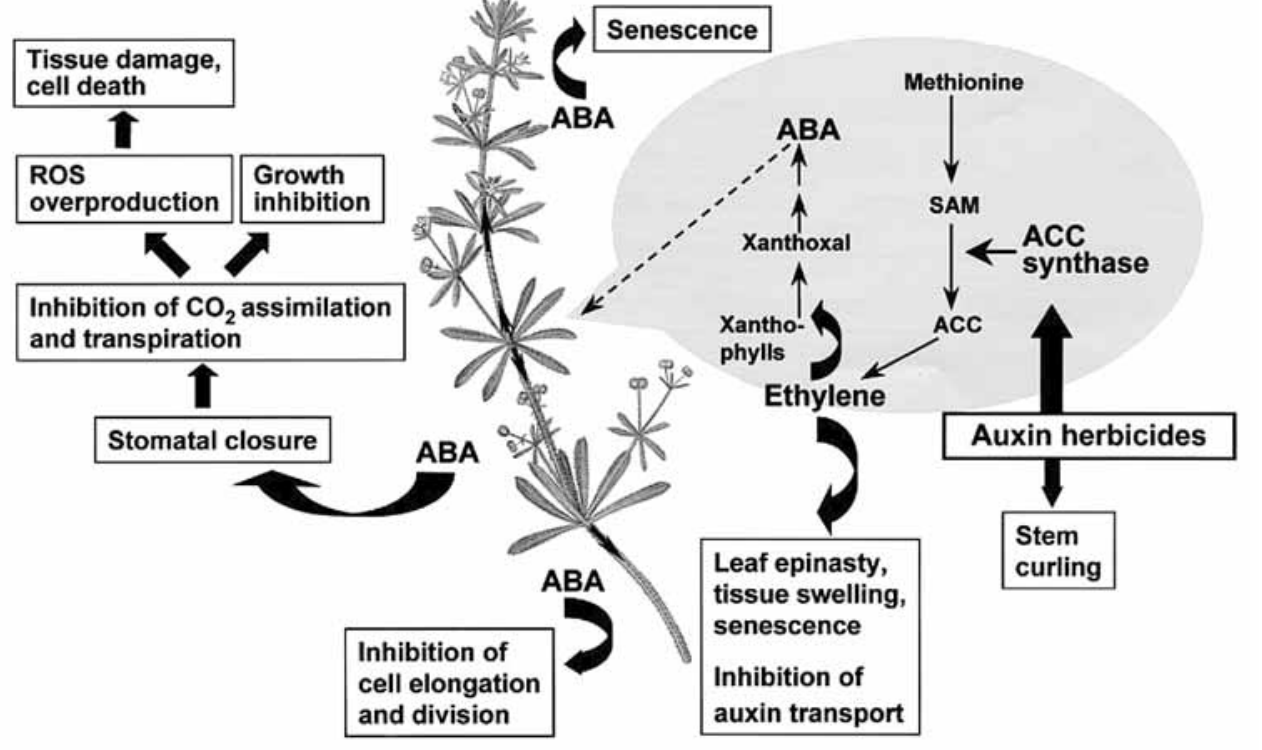

Slika 1. Model načina dejstva auksinskih herbicida kod dikotiledonih biljaka, ilustrovano na broću (Galium aparine). Auksinski herbicidi uzrokuju uvijanje stabla i indukuju biosintezu etilena putem de novo enzimske sinteze 1-aminociklopropan-1-karboksilat (ACC) sintaze u tkivu izdanka. Produkovani etilen uzrokuje epinastiju listova i bubrenje tkiva, čime se utiče i na 
lokalni nivo auksina putem inhibicije njegovog transporta. Etilen takođe stimuliše biosintezu abscisinske kiseline (ABA) uvećavajući degradaciju ksantofila do ksantoksala. ABA se distribuira u biljkama i posreduje u zatvaranje stoma, čime ograničava transpiraciju i fotosintetsku asimilaciju ugljen dioksida, što je praćeno hiperprodukcijom reaktivnih kiseoničnih vrsta (ROS). Pored toga, ABA direktno inhibira deobu i ekspanziju ćelija, a sa etilenom promoviše i senescenciju listova. Inhibicija rastenja, oštećenje tkiva i ćelija i smrt biljke su posledica opisanih procesa. SAM, S-adenozilmetionin. Preuzeto od: Grossmann (2003)

Vrlo rano je ustanovljeno da usvajanje sintetskih auksinskih herbicida zavisi kako od fizičkih faktora (kutikularna prevlaka), tako i od metaboličkih (pozitivno dejstvo svetlosti) (Sargent and Blackman, 1962, 1965). Takođe bismo dodali da primenjeni herbicidi na bazi sintetskih auksina deluju i na kvalitet semena koje produkuju tako tretirane biljke (Marinković et al., 1999). Ustanovljeno je da neki sintetski analozi auksina (npr. TIBA) inhibiraju polarni transport auksina, dok se neki vezuju za auksinske receptore (npr. (p-hlorofenoksi)-izo buterna kiselina: PCIB), delujući kao antagonosti, čime nasuprot „klasičnim“ auksinskim herbicidima, umanjuju hormonski efekat endogenih auksina (Nešković i sar., 2003). Ovo ukazuje i na fitohormonsku ulogu sintetskih auksina, tj. njihovu ulogu kao regulatora rastenja i razvića biljaka. Tako je npr. IBA efikasna u ožiljavanju reznica, a NAA se koristi za kontrolu opadanja plodova (Nešković i sar., 2003).

\section{b) giberelini i njihovi antagonisti}

Giberelini predstavlju drugu pronađenu grupu fitohormona, pronađenu od japanskih naučnika krajem 1930-tih iz filtrata fitopatogene gljive Fusarium moniliforme (polni stadijum: Gibberella fujikuroi), koja izaziva neprirodno izduživanje stabljika pirinča. Brzo su pronađene analogne supstance i u bilikama, sa više različith funkcija, kojih ističemo regulisanje izduživanja stabljika, klijanje semena, regulisanje cvetanja i sl. Nađeno je preko 100 jedinjenja sa giberelinskom aktivnošću, sva su steroidnog tipa i svi su delovi sintetskog lanca (tzv. mevalonatni sintetski put), čiji je krajnji produkt $\mathrm{GA}_{3}$ giberelin, tj. tzv. giberelna kiselina. Daljim ispitivanjem biosinteze giberelina nađeni su odgovarajući inhibitori, tj. retardanti rastenja kao npr. AMO1618, hlorholinhlorid (CCC) i fosfon D (Corbett et al., 1984; Nešković i sar., 2003). Oni svi sprečavaju aktivnost enzima kauren sintaze iz biosintetskog puta giberelina, čime se umanjuje endogeni sadržaj giberelina na vrlo nizak nivo. Tako se obustavlja ili usporava rastenje, što se često koristi radi sprečavanja suvišnog izduživanja stabla, koje vodi npr. poleganju strnih žita. Pored toga inhibitori poput tetciklasisa, paklobutrazola i unikonazola inhibiraju dejstvo tzv. mešanih monoksigenaza (Nešković i sar., 2003), koje deluju u delu sintetskog puta giberelina od ent-kaurena 
do $\mathrm{GA}_{12}$ aldehida. Dodali bismo da mnogi fungicidi iz grupe triazola imaju slično inhibitorno dejstvo na mešane monoksigenaze (Hartvig et al., 2012) i to kako kod gljiva (Corbett et al., 1984), tako i u izvesnoj meri kod biljaka (Anonymus, 2010). Iako ima drugačijih mišljenja (Malidža i sar., 1998), smatramo da inhibicija tzv. citohrom P450 oksidaza (koje pripadaju pomenutim mešanim oksidazama) od strane tzv. organofosfornih insekticida, može biti uzrok sekundarne fitotoksičnosti useva od sulfonilurea herbicida. Dodali bismo ovde da se brojni od prirodnih giberelina $\left(\mathrm{GA}_{3}, \mathrm{GA}_{4}, \mathrm{GA}_{7} \mathrm{i}\right.$ sl.) koriste kao regulatori rastenja i razvića biljaka u smislu modifikacije različitih fizioloških procesa koji utiču na kvalitet i kvantitet prinosa useva (Anonymus, 2010).

\section{c) prekursori etilena}

Etilen je jedinstven među fitohormonima, jer se na sobnoj temperaturi nalazi u gasnom stanju, pa se za njegovu zaista široku primenu (pre svega u regulaciji sazrevanja plodova) koriste supstance koje ga produkuju posle izvesnih tretmana (najčešče rastvaranjem u vodi). Jedna od takvih supstanci je i etefon, koji potpomaže sazrevanje plodova pre i posle branja, a takođe i skraćenju stabla, stimulisanju grananja, kao i inicijaciji bazalnih pupoljaka kod pojedinih ukrasnih biljaka (Corbett et al., 1984).

\section{d) citokinini i ABA}

Od drugih fitohormona, kao regulatori rastenja i razvića koriste se različiti citokinini i to u vidu sintetskih citokinina (kinetin, zeatin, benzil aminopurin-BAP) ili ekstrakata algi ili viših biljaka, koje su bogate pomenutim fitohormonima. Glavno dejstvo ove grupe fitohormona ogleda se stimulisanju deobe ćelija (Corbett et al., 1984; Nešković i sar., 2003). Nasuprot njima abscizinska kiselina (ABA) je inhibitorni (slično etilenu) fitohormon, koji promoviše dormanciju pupoljaka i semena. Valja napomenuti da se ovaj fitohormon označava i kao „hormon stresa“, pa se može koristiti kao predohrana u smislu zaštite useva, pri mogućoj pojavi značajnih stresnih epizoda, koje mogu umanjiti prinos useva (Corbett et al., 1984; Nešković i sar., 2003).

\section{e) brasinosteroidi i njihovi inhibitori; drugi regulatori rastenja}

Odskora u našem zakonodavstvu o poljoprivredi uvedena je nova kategorija nestandardnih đubriva, nazvana „druga đubriva i specijalni proizvodi“ (Anonymus, 2009). Pored već duže vreme prisutnih nekih od klasa tih nestandardnih đubriva (aminokiseline, huminske i fulvo kiseline i inhibitori denitrifikacije), uvedeni su i fitohormoni i biljni ekstrakti, koji se dosad nisu razmatrali kao posebna klasa đubriva. Dosadašnja praksa sa tim novodefinisanim klasama đubriva, duža od 
5 godina, donela je na našem tržištu, pored raznih biljnih ekstrakata (sa supstancama fitohormonskog dejstva ili regulatora rastenja; pored poznatiog preparata „Agrostemin“, tu su i razni ekstrakti algi i viših biljaka) i dosad potpuno nepoznate supstance na našem tržištu iz klase tzv. brasinosteroidnih fitohormona. Naša iskustva sa preparatom na bazi brasinosteroidnih fitohormona, zavise kako od vrste useva i vremena primene, tako i od agroekoloških uslova, ali i prateće agrotehnike (Nikolić i sar., 2010; Nikolić and Waisi, 2012; Stevanović, 2012), što ukazuje na potrebu za pažljivom primenom fitohormonskih đubriva ovog tipa, da bi se postigao puni efekat pri primeni. Šta je razlog tome? Naime, brasinosteroidni fitohormoni imaju centralnu ko-ordinacionu ulogu u rastenju i razvoju biljaka (Clouse and Sasse, 1998), pri čemu su brojni, veoma raznorodni procesi pod kontrolom ovih fitohormona. Tako je npr. njima determinisan pol biljaka (Hartwig et al., 2011), zatim njihov izgled, tj. ideotip (Hong et al., 2004; Sakamoto et al., 2005; Kir, 2010; Schulz et al., 2012), što sve utiče na prinos biljaka. Inače ovi fitohormoni su u biljkama endogeno prisutni u vrlo malim količinama, tako dok većina fitohormona deluje pri koncentracijama (endogenim ili egzogenim) od $10^{-6}$ do $10^{-7} \mathrm{M}$, brasinosteroidi deluju pri oko 1000 puta nižim koncentracijama (endogenim ili egzogenim) od njih, tj. od $10^{-8}$ do $10^{-10} \mathrm{M}$, pa i nižim! Regulacija mehanizma i načina dejstva ovih fitohormona odvija se na najmanje tri nivoa: a) sinteza brasinosteroida; b) receptori za brasinosteroide; c) signalni putevi brasinosteroida. Samim tim postaje jasnije zašto je praktična primena ovih fitohormona putem folijarnog tretmana ili natapanjem semena useva tako osetljiva. Naime, $\mathrm{u}$ jednim agroekološkim uslovima ili kod jedne kulture mogu biti efektivne jedne doze primene, koje u drugim agroekološkim uslovima ili kod drugog useva neće dati pozitivan efekat ili će dovesti i do fitotoksičnosti (Nikolić et al., 2013, 2014; Waisi et al, 2013, 2014, 2015). No to otvara treći način manipulacije ovim fitohormonima (ovde ne uzimamo u obzir genetski transformisane bilje, čija je praktična primena i u svetu u samom začetku), putem manipulacije njihove biosinteze (Fujioka and Yokota, 2003)! Naime, ključni enzim u biosintezi brasinosteroidnih fitohormona (trenutno je poznato oko 70 jedinjenja iz ove klase fitohormona) jeste već pomenuta citohrom P450 oksidaza, koja pripada klasi oksidaza mešane funkcije, tj. monoksigenaza (Fujioka and Yokota, 2003). Tokom fundamentalnih istraživanja mehanizma dejstva brasinosteroida pronađen je jedan inhibitor biosinteze ove klase fitohormona, brasinazol, koji pripada klasi triazolnih jedinjenja (Clouse and sasse, 1998). Takva istraživanja su dugo imala samo fundamentalan značaj, sve dok 2012 nije nađeno da triazolni fungicid propikonazol (Hartvig, 2012) ne inhibira na specifičan način biosintezu i akumulaciju brasinosteroida kod Arabidopsis-a, ali i kukuruza, čime se otvara mogućnost za manipulacijom endogenim sadržajem brasinosteroida u usevima, na način analogan retardantima rastenja-inhibitorima biosinteze giberelina (Nikolić, 2014)! Tim pre, št neki od pomenutih retardanata rastenja-inhibitora biosinteze giberelina takođe pripadaju klasi triazolnih jedinjenja (Nešković i sar., 2003)! 


\section{ZAKLJUČCI}

Kao što je poznato, razvoj hemijske zaštite bilja započet je pronalaskom herbicidnog dejstva 2,4-D tokom Drugog Svetskog Rata, kao posledice intenzivnih istraživačkih napora na planu proučavanja fitohormona i regulatora rastenja naučnika iz raznih zemalja u vremenu između dva svetska rata. Posle prvih decenija zajedničkog rada na rešavanju fundamentalnih, ali i praktičnih aspekata dejstva raznih fitohormonskih agrohemikalija, kao da je zavladalo zatišje, ali mišljenja smo da je zahvaljući novim fundamentalnim saznanjima poslednjih par decenija moguće unaprediti praktične aspekte primene raznih jedinja sa fitohormonskim dejstvom, a radi unapređenja poljoprivredne prakse. Ovo tim pre, što primena ovih jedinjenja koji deluju u vrlom malim dozama, zahteva pažljivu praktičnu proveru, radi optimizacije nihove primene. Mišljenja smo da je to moguć način unapređenja naše poljoprivrede, pošto ne zahteva nova ulaganja, poput razvoja novih pesticida ili regulatora rastenja, niti uvođenja novih tehnologija, poput GMO biljaka. To je moguć put ka idealu integralne poljoprivrede, a u agroekološkim uslovima Srbije. Pored toga, pojava tzv. drugih đubriva i specijalnih proizvoda (Anonymus, 2009), kao posebne klase sredstava za ishranu bilja (u koje spadaju: aminokiseline, huminske i fulvo kiseline, inhibitori denitrifikacije, fitohormoni, vitamini, biljni ekstrakti i homeopatski proizvodi), rađa potrebu za ponovnim razmatranjem problematike definisanja fitohormona i regulatora rastenja biljaka zato što nastala situacija unosi zabunu, jer kako npr. razlikovati fitohormone kao npr. herbicide i klasične regulatore rastenja biljaka, a kako kao đubriva? Mišljenja smo da ta novonastala dilema zahteva ozbiljan rad kako stručne javnosti, tako i zakonodavca, tako da bismo ovde predložili sledeće: a) sve supstance fitohormonske prirode koje deluju fitotoksično i u smislu retardanata, tj. „usporivača“ procesa rastenja i razvoja biljaka valja tretirati bilo kao herbicide, bilo kao regulatore rastenja biljaka pesticidne prirode; $b$ ) sve supstance fitohormonske prirode koje poboljšavaju kvantitet ili kvalitet prinosa useva valja tretirati kao đubriva. No, kao što rekosmo, na potezu je zakonodavac i stručna javnost.

\section{LITERATURA}

Adicott FT.: Actions on Abscission, Defoliation and Related Responses. in: HERBICIDES. Physiology, Biochemistry and Ecology. Vol. 1 (ed. LJ. Audus), 2nd edition, ACADEMIC Press, London, NewYork, San Francisko, pp. 191217, 1976.

Anonymus: Pravilnik o uslovima za razvrstavanje i utvrđivanje kvaliteta sredstava za ishranu bilja, odstupanjima sadržaja hranljivih materija i minalnim i maksimalnim vrednostima dozvoljenog odstupanja sadržaja hranljivih materija i o sadržini deklaracije i načinu obeležavanja sredstava za ishranu bilja. Službeni Glasnik R Srbije, 78/2009, 2009. 
Anonymus: Pesticidi u poljoprivredi i šumarstvu u Srbiji. 17-to izdanje (priređivači: Janjić V. i I. Elezović), Društvo za zaštitu bilja Srbije, Beograd (ISBN 978-86-83017-20-1), str. 884, 2010. Arteca RN., Bachman JM. and NB. Mandava: Effects of indole-3-acetic acid and brassinosteroid on ethylene biosynthesis in etiolated mung bean hypocotyl segments. J. Plant Physiol., 133, 430-435, 1988.

Ashton FM. and AS. Crafts: Mode of Action of Herbicides. 1st edition, A Wiley Interscience Publication, John Wiley\& Sons, NewYork, Chichester, Brisbane, Toronto. pp. 504, 1973.

Ashton FM. and AS. Crafts: Mode of Action of Herbicides. 2nd edition, A Wiley Interscience Publication, John Wiley\& Sons, NewYork, Chichester, Brisbane, Toronto. pp. 525, 1981.

Clouse SD. and JM. Sasse: BRASSINOSTEROIDS: Essential Regulators of Plant Growth and Development. Annu. Rev. Plant Physiol. Plant Mol. Biol., 49, 427-51, 1998.

Corbett JR., Wright K. and AC. Baillie: The Biochemical Mode of Action of Pesticides. ACADEMIC Press, London, NewYork, San Francisko, pp. 382, 1984.

Dragicevic V., Spasic M., Simic M., Dumanovic Z. and B. Nikolic: Stimulative influence of germination and growth of maize seedlings originating from aged seeds by 2,4-D potencies. Homeopathy, 102, 179-186, 2013.

Dragicevic V., Sredojevic S., Djukanovic L., Srebric M., Pavlov M. and M. Vrvic: The stimulatory effects of 2,4-D as hormetic on maize seedling's growth. Maydica, 52, 307-310, 2007.

Dragičević V., Sredojević S., Spasić M., Todorović M., Ivanović M., M. Vrvić: The glutathione and thiolics status in maize seedlings originating from low viable seeds, influenced by 2,4-D. ICOSECS 4, 18-21. 07. 2004., Belgrade, Book of Abstracts, Vol. II, 169, 2004.

Dragicevic V., Sredojevic S., Vrvic M., Djukanovic L. and M. Todorovic: THE MASS AND WATER PARTITIONING AS GROWTH FACTORS OF MAIZE SEEDLINGS INFLUENCED BY AGEING AND 2,4-D. Fresenius Environmental Bulletin, 13(4), 336-340, 2004.

Fujioka S. and T. Yokota: BIOSYNTHESIS AND METABOLISM OF BRASSINOSTEROIDS. Annu. Rev. Plant Biol., 54, 137-64, 2003.

Grossmann K:: A role for cyanide, derived from ethylene biosynthesis, in the development of stress symptoms. Physiol. Plant., 97, 772-775, 1996.

Grossmann K.: Mediation of Herbicide Effects by Hormone Interactions. J. Plant Growth Regul., 22, 109-122, 2003.

Hartwig T., Chuck GS., Fujioka S., Klempien A., Weizbauer R., Potluri DPV., Choe S., Johal GS. and B. Schulz: Brassinosteroid control of sex determination in maize. PNAS, Vol. 108, No. 49, 19814-19819, 2011.

Hartwig T., Corvalan C., Best N.B., Budka J.S., Zhu J-Y., Choe S. and B. Schulz: Propikonazole is a Specific and Accessible Brassinosteroid (BR) Biosynthesis Inhibitor for Arabidopsis and Maize. PloSONE, 7(5): e36625. doi:10.1371/journal.pone.0036625 (ed. Marcus grebe, Umea Plant Science Center, Sweden) (only on internet), 2012.

Hong Z., Ueguchi-Tanaka M. and M. Matsuoka: Brassinosteroids and Rice Architecture. Journal of Pesticides Sciences, 29 (3), 184-188, 2004.

Janjić V:: Hormonski herbicidi. Institut za istraživanja u poljoprivredi „Srbija“, Beograd i IP „Nauka“, Beograd, str. $278,1994$.

Jovanović V., Giba Z., Ghalawenji N. i D. Grubišić: Kultura in vitro Scopolia lurida Dunall. Program i izvodi saopštenja IX simpozijuma Jugoslovenskog društva za fiziologiju biljaka, Gozd Martuljek, I 5/62, 1990. 
Jovanović V., Grubišić D., Giba Z., Menković N. and M. Ristić: Alkaloids in hairy-root cultures of Anisodus luridus. Abstracts of Short lectures and poster presentations 39th Annual Congress on Medicinal Plant Research, Saarbrücken, Germany, 102, 1991.

Kir G.: Brassinosteroid regulation of plant height in maize. MSci thesis, Graduate Theses and Dissertations. Paper 11840, Iowa State University Digital Repository@ Iowa State University (http://lib.dr.iastate.edu/etd), Part of the Cell and Developmental Biology Commons, and the Genetics and Genomics Commons, pp. 93, 2010.

Malidža G., Živanović M. i B. Konstantinović: Značaj interakcije između organofosfornih insekticida i sulfonilurea herbicida za njihovu bezbednu primenu u kukuruzu. u: »Pojava, štetnost i suzbijanje kukuruzne zlatice Diabrotica virgifera virgifera Le Conte«, (ur. D. Čamprag), Društvo za zaštitu bilja Srbije, Beograd, str. 123-132, 1998.

Marinković I., Janjić V., Knežević D., Cupać S., Nikolić B. and Lj. Jovanović: Effects of Hormone herbicides on Wheat (Triticum aestivum L.) Seed Germination. Acta herbologica, Vol. 8, No 1, 63-68, 1999.

Nešković M., Konjević R. i Lj. Ćulafić: Fiziologija biljaka. NNK-Internacional, Beograd, str. 586, 2003.

Nikolić B., Dragičević V., Waisi H., Đurović S., Milićević Z., Spasojević I. and M. Brankov: IMPACT OF ROOT MANIPULATION AND BRASSINOSTEROIDS ON GROWTH, PHOTOSYNTHESIS AND THERMODINAMICS OF MAIZE AT LOWER TEMPERATURES. in: PHYSICAL CHEMISTRY 2014, 12th International Conference on Fundamental and Applied Aspects of Physical Chemistry (ISBN 978-86-82475-31-6), eds. Ž. Čupić and S. Anić; September 22-26, 2014, Belgrade, Serbia, pp. 477-481, 2014.

Nikolić B., Ugrinović M., Đurović Sanja, Zdravković Jasmina i Z. Milićević: Uticaj drugih đubriva i specijalnih proizvoda na hortikulturne biljke. 1. Prinos i komponente prinosa jabuke i paradajza. Zaštita bilja, 61(4), 301313, 2010.

Nikolić B. and H. Waisi: Effect of simultaneous application brassinosteroids and reduced doses of fungicides on pomological characteristics and yield of apple (Malus domestica L.). Proceedings of abstracts of 1st International Brassinosteroid Conference, Barcelona June 27th - 29th 2012, ed. AOPC/ Brassinosteroid 2012 (E-mail: congress@aopc.es), CSIC, Centre de Recerca en Agrigenòmica, Barcelona Spain, (edited only in electron form in USB device), pp. 44 (Poster No. 26), 2012.

Nikolić B., H. Waisi, Dragićević V., Marisavljević D., Pavlović, D. Jovanović V. and S. Đurović: The effect of different light and nitrogen growth regimes on brassinosteroid activity in maize plants. Proceedings of abstracts of 20th Symposium of the Serbian Plant Physiology Society (ISBN: 978-86-912591-2-9 SPPS), Subotica, pp. 49-50 (ed. Serbian Plant Physiology Society and Institute for Biological Research „Siniša Stankovićc, Univercity of Belgrade), 2013.

Sakamoto T., Morinaka Y., Ohnishi T., Sunohara H., Fujioka S., Ueguchi-Tanaka M., Mizutani M., Sakata K., Takatsuto S., Yoshida S., Tanaka H., Hidemi Kitano H. and M. Matsuoka: Erect leaves caused by brassinosteroid deficiency increase biomass production and grain yield in rice. Nature Biotechnology, 24, 105-109, 2005.

Sargent JA and GE Blackman: Studies on Foliar Penetration. 1. Factors controlling the entry of 2,4-dichlorophenoxyacetic acid. J. Exp. Bot., Vol. 13, No. 39, 348-368, 1962.

Sargent JA and GE Blackman: Studies on Foliar Penetration. 2. The Role of Light in Determining the Penetration of 2,4-dichlorophenoxyacetic acid. J. Exp. Bot., Vol. 16, No. 46, 24-47, 1965.

Schulz B., Best N., Budka J., Chuck G., Hartwig T., Johal G. and DP. Potluri: The grass-like transcription factor upright leafe angle1 (URL1) encodes a monocot-specific brassinosteroid function for leaf angle control in maize. Proceedings of abstracts of 1st International Brassinosteroid Conference, Barcelona June 27th - 29th 2012, ed. 
AOPC/ Brassinosteroid 2012 (E-mail: congress@aopc.es), CSIC, Centre de Recerca en Agrigenòmica, Barcelona Spain, (edited only in electron form in USB device), pp. 43 (Poster No. 24), 2012.

Sredojević S., Dragičević V., Pajić Z., Radenović Č., Srebrić M., Stefanović L., Vrvić M. i J. Videnović: Promena sadržaja azota i fosfora kod klijanaca linija i hibrida kukuruza pod uticajem 2,4-D. XIV simpozijum JDFB, Goč, 18.-21. Jun 2001., Zbornik izvoda, pp. 48-49, 2001.

Stevanović M., Trkulja N., Nikolić B., Dolovac N. and Ž. Ivanović: EFFECT OF SIMULTANEOUS APPLICATION OF BRASSINOSTEROIDS AND REDUCED DOSES OF FUNGICIDES ON VENTURIA INAEQUALIS. in: Proceedings of International Symposium: Current Trends in Plant Protection, Belgrade 25-28 September 2012 (ISBN: 978-86-910951-1-6; UDK: 634.11-248.231), ed. Institute for Plant Protection and Environment, pp. 379$384,2012$.

Waisi H., Dragičević V., Nikolić B., Đukanović L., Živanović M., Jovanović V. and S. Đurović: Preliminary observation of the effect of different concentration of 24-epibrassinolide on germination of seeds of two maize hybrids. in: Proceedings of abstracts of 20th Symposium of the Serbian Plant Physiology Society (ISBN: 978-86-9125912-9 SPPS), Subotica, pp. 33 (ed. Serbian Plant Physiology Society and Institute for Biological Research „Siniša Stanković", Univercity of Belgrade), 2013.

Waisi H., Kosović A., Krstić Đ., Milojković-Opsenica D., Nikolić B., Dragičević V. and J. Trifković: Polyphenolic profile of maize seedlings treated with 24-epibrassinolide. Journal of Chemistry, Vol.: 2015, Article ID 976971, 10 pages, http://dx.doi.org/10.1155/2015/976971 (in press), 2015.

Waisi H., Nikolić B., Dragičević V., Pavlović D., Vujičic M. and S. Đjurovic: Influence of brassinosteroid based fertilizer on the germination of two maize hybrids. in: Book of Abstracts of V Congress of the Serbian Genetic Society (ISBN 978-86-87109-10-0), ed. Branka Vasiljević and Snežana Mladenović-Drinić, 28 September-02 Oktober 2014, Belgrade (erlier Kladovo), Serbia, pp. VII-69 Poster, 2014. 